\title{
Fantasia, analogia e narcisismo: Um argumento contra a tradução de "Trieb" por "instinto"1
}

\section{Fantasy, analogy and narcissism: An argument against the use of "instinct" as a translation of "Trieb"}

\author{
Léa Silveira \\ lea@dch.ufla.br \\ (Universidade Federal de Lavras, Minas Gerais, Brasil)
}

Resumo: 0 artigo discute uma passagem do texto " 0 inconsciente" - aquela em que Freud traça uma analogia entre as fantasias e os "instintos dos animais" - apontando-a como algo decisivo para 0 debate sobre a tradução do termo Trieb. Sua análise resulta na defesa da impossibilidade de vertê-lo por "instinto", acenando para a impossibilidade correlata de se proceder a uma redução dos principais conceitos freudianos à biologia. Se a atitude de criticar tal redução foi por vezes caracterizada como narcisismo, será necessário constatar que tal denúncia se vale de um conceito concebível apenas quando já se admitiu a distância entre natureza e cultura.

Palavras-chave: Psicanálise, Freud, tradução, Trieb.
Abstract: The paper discusses a passage from the text "The unconscious" - the one in which Freud draws an analogy between fantasies and "animal instincts" - indicating it as something decisive to the debate on the translation of the term Trieb. Its analysis results in the defense of the impossibility of choosing "instinct" to translate Trieb, signaling to the related impossibility of carrying out a reduction of the major Freudian concepts to biology. If the attitude of criticizing such a reduction was sometimes characterized as narcissism, it will be necessary to state that this complaint relies on a concept that is conceivable only after the admission of the distance between nature and culture.

Keywords: Psychoanalysis, Freud, translation, Trieb.

DOI: http://dx.doi.org/10.11606/issn.2318-9800.v19i1p189-204

1. Trabalho apresentado no V Congresso Internacional de Filosofia da Psicanálise, São Paulo, 2013. Agradeço a Luiz Marcos da Silva Filho, Elis Joyce Gunella e João Geraldo Martins da Cunha pela leitura do manuscrito e por suas sugestões. 


\begin{abstract}
"On est moins tenté d'incliner un système dans le sens ou l'on se plairait à le contempler, quando on a tâché de suivre de près le travail d'esprit par lequel se sontpeu à peudéfinies et enchainées les pensées qui le composent; on se défie certainement da vantage de cesjeux de réflexion qui, sous prétexte de découvrir la signification profonde d'une pbilosopbie, commencent par ennégliger la signification exacte."
\end{abstract}

(Victor Delbos)

No contexto do debate atual sobre a tradução da obra freudiana no Brasil, um dos pontos mais controversos é certamente a tradução do termo "Trieb". A opção por vertê-lo por "instinto" parece ser notadamente marcada pela rejeição da alternativa "pulsão". Tal rejeição pode ler lida como algo alicerçado num posicionamento contrário à psicanálise lacaniana, uma vez que foi sobretudo por intermédio da leitura de Lacan que o arcaísmo tornou-se galicismo em português. Em larga medida, tudo se passa como se, ao optar pela recusa do termo "pulsão", o estudioso, o psicanalista ou o tradutor dissessem algo como: "Freud não é Lacan e não podemos correr o risco de sobrepor o segundo ao primeiro sob pena de não compreendermos os pressupostos, a arquitetura e as diretrizes da teoria freudiana." A meu ver, essa alegação é exatamente correta, embora não acarrete necessariamente a rejeição do termo "pulsão". Não é em Lacan que encontramos aquilo que foi pensado por Freud, apesar da afamada expressão "retorno a Freud" sugerir, por vezes, o contrário. Embora seja possível dizer que, em certo sentido, ambas as obras se voltam para o mesmo objeto - o inconsciente -, se não as separarmos em suas respectivas inteligibilidades, simplesmente não compreenderemos nem uma nem outra. Entendo, ademais, que isso não é demérito algum para a teoria lacaniana, mas o contrário. Lacan foi o pensador que tentou retirar a psicanálise dos impasses do psicologismo, nela introduzindo argumentos de cunho transcendental. Esse movimento, que inexiste em Freud, é, a meu ver, o que permite situar epistemologicamente sua teoria. Poderíamos, é claro, aproximar - como era, aliás, a intenção de Lacan - a expressão "retorno a Freud" de um outro sentido, que seria ao mesmo tempo clínico e político-institucional, mas isto estaria já muito distante do foco deste artigo. O que quero dizer, à guisa de introdução, é apenas que a rejeição de "pulsão" para verter "Trieb" parece, à primeira vista, acenar para uma justificativa legítima: o esforço de tomar distância relativamente às estratégias de "lacanizar" Freud, estratégias que, anacronicamente, projetam sobre este um outro território epistemológico. 
Poder-se-ia asseverar, é claro, que não é isso o que está em jogo e que "instinto" seria objetivamente a melhor tradução de Trieb. Quero, então, trazer para o debate um argumento que parece contradizer isso e que se restringe à análise de algumas passagens escritas por Freud. Rapidamente indicado por Laplanche e Pontalis, ${ }^{2}$ ele não parece ter sido retomado nas discussões mais recentes suscitadas no Brasil pela opção, alegadamente descompromissada e supostamente inócua, do tradutor P. C. de Souza ${ }^{3}$ pelo termo "instinto" para verter "Trieb" em português. Se o retomo aqui é por considerar nele haver algo de caráter decisivo. Refiro-me à analogia que Freud traça entre as fantasias e os instintos dos animais. No texto $\mathrm{O}$ inconsciente, ele a formula de um modo apenas alusivo ao dizer que, "se há no homem formações psíquicas herdadas, algo análogo ao instinto [Instinkt] dos animais, isso é o que constitui o núcleo do Ics." Como se sabe, esse é um dos poucos momentos em que Freud emprega o termo "Instinkt". Mas o leitor parece ficar aqui um tanto desamparado no que diz respeito à interpretação deste raro uso: o que são essas formações psíquicas herdadas e qual o sentido dessa analogia?

2. LAPLANCHE, J. \& PONTALIS, J.-B. Vocabulaire de lapsychanalyse. $13^{\mathrm{a}}$ ed. Paris: PUF, 1997, p. 203 (verbete "instinto").

3. Cf. a nota "Esta edição", prévia a cada volume editado pela Companhia das Letras, na qual lemos: "No tocante aos termos considerados técnicos, não existe a pretensão de impor as escolhas aqui feitas, como se fossem absolutas. Elas apenas pareceram as menos insatisfatórias para o tradutor, e os leitores e psicanalistas que empregam termos diferentes, conforme suas diferentes abordagens e percepções da psicanálise, devem sentir-se à vontade para conservar suas opções. Ao ler essas traduções, apenas precisarão fazer o pequeno esforço de substituir mentalmente 'instinto' por 'pulsão', 'instintual' por 'pulsional', 'repressão' por 'recalque', ou 'Eu' por 'ego', exemplificando. No entanto, essas palavras são poucas, em número bem menor do que geralmente se acredita." (DE SOUZA, P. C. Esta edição. In: FREUD, S. Obras completas, v. 14. Trad. P. C. de Souza. São Paulo: Companhia das Letras, 2010, p. 12)

4. FREUD, S. Lo inconciente (1915). In: ___. Obras completas, v. XIV. $2^{\mathrm{a}}$ ed. Tradução de J. L. Etcheverry. Buenos Aires: Amorrortu Editores, 2010, pp. 191-192. "Wenn es beim Menschen ererbte psychische Bildungen, etwas dem Instinkt der Tiere Analog es gibt, so macht dies den Kern des Ubwaus". FREUD, S. Das Unbewußte. In: Psychologie des Unbewußten (1915). Studienausgabe, v. III, Frankfurt am Main: Fischer Taschenbuch Verlag, 2000, p. 154 . 
Três anos depois, Freud publicou o caso clínico do Homem dos Lobos $^{5}$, texto que, por sua vez, fornece os recursos necessários para entender que tipo de relação está sendo traçada por ele entre instinto e "formações psíquicas herdadas". Pois lemos aí que

se se considera a conduta do menino de quatro anos de idade [isto é, do paciente em questão] diante da cena primária reativada (...), dificilmente poder-se-á afastar a concepção de que no menino coopera uma espécie de saber difícil de determinar, algo como uma preparação para entender. Em quê isso possa consistir, eis aí algo que escapa a toda representação; dispomos apenas de uma notória analogia com o vasto saber instintivo dos animais. ${ }^{6}$

Lemos, então, que o sentido da analogia é que esta é construída entre os polos do instinto e da fantasia da "cena primária" e ainda que ela se refere à existência de um saber.

Observemos, de saída, que a leitura do trecho reproduzido como, ademais, de tantos outros escritos por Freud - deixa claro que não é verdade que inexista, para o autor, qualquer vínculo entre pulsão e padrão herdado de comportamento; esse vínculo é imputado às fantasias primitivas, que são análogas aos instintos dos animais.

Mas, quanto ao sentido de "analogia", a meu ver, a hipótese de leitura mais plausível é que, no trecho citado, ele consiste na referência, ainda que rápida, a um "raciocínio por analogia". Grosso modo, um

5. Cujo primeiro rascunho foi redigido em 1914.

6. FREUD, S. De la historia de uma neurosis infantil (1918[1914]). In:

Obras completas, v. XVII, $2^{a}$ ed. Trad. J. L. Etcheverry. Buenos Aires: Amorrortu Editores, 2010, p. 109, grifos meus com exceção do último."Wenn man das Verhalten des vier jährigen Kindes gegen die reaktivierte Urszene in Betracht zieht (...), kann man die Auffassung schwer von sich weisen, daß eine Art von schwer bestimmbarem Wissen, etwas wie eine Vorbereitung zum Verständnis, beim Kinde dabei mit wirkt. Worin dies bestehen mag, entzieht sich jeder Vorstellung; wir haben nur die eine ausgezeichnete Analogie mit dem weitgehenden instinktiven Wissen der Tiere zur Verfügung". FREUD, S. Aus der Geschichte einer infantile Neurose (1918[1914]). In: Zwei Kinderneurosen. Studienausgabe, v. VIII, Frankfurt am Main: Fischer Taschenbuch Verlag, 2000, p. 230.

7. Cf. LALANDE, A. Vocabulaire technique et critique de la pbilosopbie (1902-1923). $6^{a}$ ed.Paris: PUF, 1951, pp. 51-53. Não faz parte dos meus objetivos aqui problematizar o sentido filosófico seja da analogia seja do raciocínio por 
raciocínio por analogia toma-a por fundamento no sentido da apresentação de uma mesma relação entre dois pares de termos que se relacionam dois a dois. $\mathrm{O}$ modelo de analogia tomada nesse sentido é, como se sabe, a proporção matemática e o tipo de raciocínio que ela pode promover consiste em passar de três termos conhecidos (dois de uma primeira relação e um da segunda relação) para o conhecimento, ao menos relativo, do quarto termo tomado inicialmente como desconhecido. No caso que nos interessa aqui, o termo desconhecido, cujo conhecimento é almejado pelo estabelecimento da analogia, são as fantasias ou as formações psíquicas herdadas: Freud diz que não é possível imaginar em quê elas consistem a não ser por uma analogia com os instintos dos animais. Estabelece, assim, nas últimas páginas do relato do caso do Homem dos Lobos, um isomorfismo entre duas relações, sendo a primeira uma relação entre os instintos e os animais e, a segunda, uma relação entre as fantasias herdadas - ou os "esquemas" ${ }^{\text {"8 }}$ congênitos - e os seres humanos. Freud faz isso para concluir que é possível conhecer algo a respeito do quarto termo: é possível concluir que aquilo que está em jogo em tais fantasias é que, no transcurso das gerações, algo é herdado no sentido de um saber ${ }^{9}$. Assim, se é condição da analogia que os termos emparelhados em cada relação submetida à semelhança formal sejam distintos entre si, resta claro que não é possível vislumbrar aqui nenhuma possibilidade de sustentar que Freud esteja delineando uma identidade entre fantasia e instinto.

Uma possível objeção, a essa altura, seria algo como: "não há elementos suficientes no trecho citado para dizer que o que está em questão é um raciocínio por analogia; na verdade, o trecho do Homem dos Lobos não vai muito além do sentido do trecho de $\mathrm{O}$ inconsciente porque seria possível defender que o termo 'analogia' é lá empregado em seu uso corrente, de modo que aquilo que Freud está instituindo é uma mera semelhança ${ }^{10}$ entre termos e não entre relações - ou seja, uma semelhança entre 'formações psíquicas herdadas' e 'instintos'". Ora, mas nesse caso tampouco a relação poderia caminhar para uma identidade. Isso simplesmente porque o sentido de uma semelhança

analogia. Tal problematização não interferiria, assim acredito, de modo relevante na conclusão do argumento que quero apresentar.

8. Cf. FREUD, S. De la historia de uma neurosis infantil, p. 109.

9. Cf. Idem, pp. 108-110.

10. Cf. LALANDE, Vocabulaire technique et critique de la philosopbie, p. 51. 


\section{Léa Silveira}

não é uma identificação. Tal sentido não consiste em identificar os termos inseridos na comparação, mas em indicar traços compartilhados, preservando-se, no entanto, uma distinção. Quando uma semelhança é traçada, isso só pode ser realizado sob a condição da diferença entre os termos. Quando se diz que A é semelhante a B, o pressuposto necessário implícito é que $\mathrm{A}$ é diferente de $\mathrm{B}$. Não faria sentido dizer, por exemplo, que A é semelhante a $\mathrm{A}$, pois isso correria o sério risco de simplesmente ferir um princípio lógico básico ${ }^{11}$. Não parece haver motivo para não pensarmos algo tão simples quanto o seguinte: se Freud precisou dizer que as fantasias herdadas são semelhantes ao instinto, isso só pode significar que não podemos lhe atribuir a suposição de uma identidade entre fantasias herdadas e instinto. Caso contrário, ele teria dito apenas: "as formações psíquicas herdadas são instintos $^{112}$. Se Freud porventura tivesse formulado algo assim, a ideia que ele estaria sustentando seria a seguinte: algo que o ser humano tem em comum com os animais - o instinto - ocupa o lugar da mais alta relevância na teoria psicanalítica. Em vez disso, o que ele disse foi: aquilo que os instintos fazem com os animais, as fantasias herdadas fazem com os seres humanos, isto é, estabelecem uma tendência comportamental herdada incontornável, que é o núcleo do inconsciente.

Antes que se objete ainda que, na continuidade do texto sobre o Homem dos Lobos, Freud usa o adjetivo "instintivo" para qualificar essa herança, gostaria de antecipar que o movimento do texto, pelos motivos que acabo de apresentar, não nos permite suprimir o índice a partir do qual este adjetivo é empregado e esse índice, como já está claro, é o da analogia, leitura, aliás, corroborada pelo uso do termo "instinktartigen"13, que significa algo como "com as características do instinto" ${ }^{\prime \prime}$.

11. Que obviamente é o princípio de identidade.

12. Ao redigir essas últimas frases, dei-me conta de que talvez isso não passe de um truísmo. Tal sensação, no entanto, não me dissuade do argumento. $\mathrm{Na}$ verdade, ela apenas introduz outra questão: por que motivo trouxemos o debate a esse ponto? Isto é, por que motivo o debate sobre a tradução de Freud chegou ao ponto da necessidade do óbvio?

13. FREUD, S. Aus der Geschichte einer infantile Neurose, p. 230.

14. Separar o trecho em que Freud usa o adjetivo "instinktiv" para interpretá-lo como o estabelecimento de uma sinonímia entre fantasias originárias e ins- 
Além disso, a fantasia herdada não é a pulsão, ponto que exige a referência ao trecho do Vocabulário que mencionamos no início. Nele, os autores alegam que, quando Freud "se pergunta '...se existem no homem formações psíquicas hereditárias, algo de análogo ao instinto dos animais', não é na pulsão que ele vê esse equivalente, mas nesses 'esquemas filogenéticos hereditários' que são as fantasias originárias $(\ldots)^{\prime \prime 15}$. Ora, Trieb é o fato de que a necessidade biológica ou a função corporal, sob a forma de estímulo endógeno com força constante, ativa no ser humano um trabalho de organização das representações em fantasias. Trieb está relacionado com aquilo que, no ser humano, é análogo ao instinto dos animais. Mas Trieb não é, em si mesmo, fantasia; é a força que conduz à sua produção. Eis um ponto que parece marcar sobremodo tal distinção: o recurso à pulsão - ao contrário do recurso à semelhança entre as fantasias filogenéticas e os instintos dos animaisnão é, segundo Freud, um recurso que se deve adotar apenas quando se esgota a análise daquilo que foi adquirido individualmente. A narração dos eventos da história individual é não apenas totalmente atravessada, mas tornada mesmo possível pelo recurso à pulsão. Já as referências aos fatores hereditários, à aquisição filogenética, diz Freud, "só me parecem admissíveis quando a psicanálise, obedecendo ao itinerário correto das instâncias, se depara com a pista do que foi herdado após penetrar pelos estratos do que foi adquirido individualmente"116. A referência à analogia com o instinto só ganha, portanto, direito de cidadania na teoria quando a reflexão alcança esse limite. Antes dele, há Trieb e nenhuma referência a uma comparação com o instinto. Diz Freud, ainda a esse respeito e comentando a posição de Jung: "(...) considero metodologicamente incorreto recorrer a uma explicação que parta da filogênese antes de ter esgotado as possibilidades da ontogênese $(\ldots)^{\prime 17}$.

tinto seria, assim, um equívoco resultante da subtração de teses ao movimento do texto que as apresenta.

15. LAPLANCHE, J. \& PONTALIS, J.-B. Vocabulaire de la psychanalyse, p. 203.

16. FREUD, S. De la historia de uma neurosis infantil, p. 110, grifo meu. "Sie erscheinen mir erst zulässig, wenn die Psychoanalyse in Einhaltung des korrekten Instanz enzugesauf die Spurendes Ererbtengerät, nachdem sie durch die Schichtung des individuell Erworbenen hindurch gedrungenist." FREUD, S. Aus der Geschichte einer infantile Neurose, p. 230.

17. FREUD, S. De la historia de uma neurosis infantil, p. 89. "(..) aberich halte es für methodisch unrichtig, zur Erklärung aus der Phylogenese zugreifen, 


\section{Léa Silveira}

Essas considerações me parecem ser suficientes para sustentar que, no relato do caso do Homem dos Lobos, quando Freud escreve "instinktiven"18 cinco páginas depois de ter escrito "triebbafte"19, seria necessário forçar muito nas tintas para conseguir atribuir um uso tão claramente discriminado dos termos a um fator casual qualquer.

Se fica claro, assim, que não há para Freud sequer analogia entre instinto e pulsão, tanto mais difícil seria encontrar, a despeito dessa demarcação, uma identificação entre os dois termos que respaldasse a escolha de tradução de Trieb por instinto.

O problema - de profundas consequências políticas - não parece, assim, ser um problema político em primeiro plano ${ }^{20}$ : se não houvesse distinção entre animal e ser humano ou entre natureza e cultura em Freud e precisássemos, por motivos ético-políticos, defender essa distinção, acaso não seria possível fazer isso a contrapelo da teoria freudiana? Acaso nos aferraríamos indefinidamente a argumentos ad bominem de um modo tal que não pudéssemos - se isso fosse necessário quanto à questão que abordamos agora - discordar de Freud, colocarmo-nos contra ele, no sentido da construção de argumentos relativos ao mesmo campo de fenômenos por ele abordado? $\mathrm{O}$ que quero dizer com isso é que o problema, antes de ser político, parece ser um problema de exegese.

Convém assim observar que a compreensão da impossibilidade de designar o conteúdo semântico de "Trieb" pela palavra "instinto" a partir de elementos presentes no próprio texto de Freud converge com a leitura de que noções e conceitos maiores de sua teoria - tais como mal-estar, complexo de Édipo e recalque - simplesmente não poderiam

eheman die Möglichkeiten der Ontogenese erschöpft hat (...)". FREUD, S. Aus der Geschichte einer infantile Neurose, p. 210.

18. Idem, p. 230.

19. Referindo-se ao fundamento pulsional da crença religiosa do paciente (Idem, p. 227).

20. Para um ponto de vista contrário a respeito desse ponto, cf. ESTÊVÃO, I. Retorno à querela do Trieb: Por uma tradução freudiana. Cadernos de filosofia alemã, São Paulo, v. XIX, 2012, pp. 79-105. 
existir como noções e conceitos estruturantes caso ela fosse uma teoria voltada para a redução da explicação de fenômenos humanos à biologia.

Vou me contentar aqui com observações muito rápidas sobre os conceitos que acabo de mencionar para então retomar logo o fio condutor da argumentação. Sabemos que, para Freud, não há mal-estar na natureza porque é a cultura que exige uma renúncia pulsional produtora de um novo regime de funcionamento psíquico. Sabemos que a tentativa de universalizar o complexo de Édipo em Totem e tabu o vincula à exogamia como fenômeno cultural - e, afinal, o que lemos nesse livro senão que não há cultura sem complexo de Édipo e que não há complexo de Édipo sem cultura? Sabemos que o inconsciente no sentido freudiano só existe após o recalque originário com a separação entre representação-de-coisa e representação-de-palavra, que instaura a divisão entre os sistemas, de modo que podemos dizer que, sem linguagem, não haveria recalque. Trata-se aqui, necessariamente, de uma linguagem desenvolvida, com vocabulário suficiente para que seja tecida a rede de associações, com sintaxe suficiente para permitir que a intensidade das representações se dissipe sob a incidência do processo secundário ${ }^{21}$.

Evidentemente, mal-estar, complexo de Édipo e recalque estão necessariamente vinculados à biologia e à natureza; não se trata de negar isso. Não se trata de negar a existência, na obra de Freud, de vários argumentos cuja origem e/ou compleição reside na biologia. Aliás, o lugar da teoria em que argumentos desse tipo são mais fortes é o lugar das fantasias originárias e não o da pulsão, sendo isso o que diz o próprio Freud, ao escrever para Ferenczi, em 1917, que, com a hipótese filogenética, "a PsA terá entregue seu cartão de visita à biologia ${ }^{\prime \prime 2}$; note-se bem: não é com a pulsão que esse convite é entregue, mas com a hipótese filogenética (e, portanto, com o diálogo que

21. A esse propósito, observemos, ainda que lateralmente, que a correta rejeição da psicanálise lacaniana como chave de leitura de Freud não deve nos conduzir ao extremo oposto da miopia diante do papel fundamental que este estabelece para a linguagem, como fenômeno cultural.

22. Carta de 28 de janeiro de 1917, trecho citado por GRUBRICH, I. Metapsychology and metabiology - On Sigmund Freud's draft Overview of the transference neuroses. In: FREUD, S. A pbylogenetic fantasy - Overview of the transference neuroses. Cambridge, Massachusetts: Harvard University Press, 1987, p. 94. 
ela precisa encampar com o evolucionismo). Não se trata de negar que os conceitos metapsicológicos possuem importantes alicerces biológicos - sendo a consideração do modelo arco-reflexo como modelo do aparelho psíquico talvez o principal deles-,nem que, em Freud, a pulsão, sempre vinculada a cada um desses conceitos, é um estímulo endógeno, que o corpo humano está inserido numa cadeia evolutiva, que os processos psíquicos exigem o cérebro, embora ele tenha abandonado a linguagem neurológica do Projeto em prol de uma linguagem psicológica. Trata-se de reconhecer que a lógica do mal-estar, do complexo de Édipo e do recalque não é uma lógica redutível à biologia.

Acredito que destinar o problema apenas ao campo político corre o risco de empobrecer a posição argumentativa aí implicada, porque então tudo se passaria como se, em função de posturas políticas atuais, escolhêssemos ler Freud de uma maneira ou de outra, ambas as maneiras sendo franqueadas pela letra de seus textos. Acredito ser possível encontrar nos textos freudianos aquilo que ele designa por Trieb - ainda que a título de conceito provisório, obscuro e indeterminado - e o fato desse designado não ser o instinto. A questão, assim, não é, em primeiro lugar, que uma teoria freudiana reduzida à biologia teria efeitos deletérios. A questão é que uma biologização da teoria freudiana parece, por um lado, ter que passar ao largo de afirmações terminantes do autor como aquelas acima exploradas e, por outro, esvaziá-la de especificidade. Isto em um sentido epistemológico, aliás, muito preciso: se, aos olhos de Freud, a psicanálise fosse redutível à biologia, ele não teria motivos para alegar reiteradamente ter criado uma disciplina científica autônoma.

\section{$*$}

Não é raro que a crítica da sinonímia entre Trieb e instinto seja alvejada com a acusação de mera postura narcísica. Essa investida também a encontramos em P. C. de Souza, quando ele diz que "talvez seja lícito afirmar que no fundo é o narcisismo humano (a "inconsciente vaidade humana") que se manifesta na insistência em distinguir resolutamente um Instinkt animal de um Trieb humano". ${ }^{23}$ Poder-se-ia dizer, embora Souza não o faça, que esse haveria sido um argumento

23. DE SOUZA, P. C. As palavras de Freud. São Paulo: Companhia das Letras, 2010, p. 261. 
do próprio Freud e essa alegação provavelmente iria recorrer a um trecho de Moisés e a religião monoteísta em que este diz o seguinte: ${ }^{24}$

Reduzimos o abismo excessivo que a arrogância humana de épocas anteriores abriu entre o homem e o animal. Se os chamados 'instintos' dos animais, que lhes permitem comportar-se desde o início mesmo na nova situação vital como se ela fosse antiga, outrora familiar; se a vida instintiva dos animais admite em geral uma explicação, só pode ser que trazem congênitas para sua nova existência própria as experiências de sua espécie, isto é, que guardam em seu interior recordações do que foi vivenciado por seus antepassados. E em um animal humano as coisas não seriam, no fundo, diferentes. Sua própria herança arcaica corresponderia aos instintos dos animais, ainda que seu alcance e conteúdo sejam diversos. ${ }^{25}$

Preciso, então, deter-me na análise desse trecho para tentar averiguar se ele de fato põe água no moinho adversário. A primeira coisa a ser observada é que essa reflexão não está, mais uma vez, voltada para uma problematização de Trieb. Em segundo lugar, quando Freud diz que é arrogância ou orgulho do ser humano julgar-se superior ao animal, ele emprega os seguintes termos: "reduzimos o abismo excessivo" entre a humanidade e os animais. Ele não diz, note-se bem,

24. Isso é defendido em SIMANKE, R. A psicanálise freudiana e a dualidade entre ciências naturais e humanas. Scientiae Studia, São Paulo, v. 7, 2009, pp. 221-236.

25. FREUD, S. Moisés y la religión monoteísta. In: Obras completas, v. XXIII, $2^{\mathrm{a}}$ ed. Tradução de J. L. Etcheverry. Buenos Aires: Amorrortu Editores, 2010, pp. 96-97, grifos meus) "Wir verringern die Kluft, die frühere Zeiten menschlicher Überhebung allzuweit zwischen Mensch und Tier aufgerissen haben. Wenn die sogenannten Instinkte der Tiere, die ihnen gestatten, sich von Anfang an in der neuen Lebenssituation so zu benehmen, als wäre sie eine alte, längst vertraute, wenn dies Instinktleben der Tiere überhaupt eine Erklärung zuläßt, so kann es nur die sein, daß sie die Erfahrungen ihrer Art in die neue eigene Existenz mitbringen, also Erinnerungen an das von ihren Voreltern Erlebte in sich bewahrt haben. Beim Menschentier wäre es im Grunde auch nicht anders. Den Instinkten der Tiere entspricht seine eigene archaische Erbschaft, sei sie auch von anderem Umfang und Inhalt". (FREUD, S. Der Mann Moses und die monotheistische Religion: Drei Abhandlungen (1939[1934-38]). In: Fragen der Gesellschaft Urspriunge der Religion. Studienausgabe, v. IX, Frankfurt am Main: Fischer Taschenbuch Verlag, 2000, p. 547). 
"suprimimos esse abismo". De fato, sob certo aspecto, tranquilamente se percebe que essa separação é diminuída porque o que Freud está dizendo é que ele encontrou aquilo que, no ser humano, desempenha um papel equivalente àquele dos instintos no caso dos animais. Freud diz que a posição do "animal humano" não seria diferente da posição dos outros animais, porque assim como estes transmitem padrões de comportamento de geração em geração pela via dos instintos, os seres humanos também transmitem padrões de comportamento de geração em geração - só que, nesse caso, isso ocorre, não pela via dos instintos, mas pela via das fantasias, que correspondem, nos seres humanos, àquilo que os instintos são para os animais. Note-se, mais uma vez, que em nenhum momento, nem aqui e nem em nenhum outro lugar, Freud diz que as fantasias são instintos. Ao contrário, o que Freud considera necessário apontar logo na sequência é que a herança arcaica dos seres humanos constituída pelas fantasias é diferente da herança instintiva, segundo suas palavras, "em seu alcance e em seu conteúdo."

Outra observação importante sobre o argumento de que a rejeição do termo "instinto" se fundamenta numa arrogância narcísica é que ele toma como ponto de partida, para a caracterização da arrogância, um juízo de valor que procura indicar o caráter superior da cultura relativamente à natureza. Esquece-se, no entanto, que isso aponta, na verdade, para um poço de ambiguidade porque, apesar da aposta do Freud iluminista no porvir de uma prevalência da visão de mundo racional-científica, não é certo que a civilização, sempre caracterizada negativamente, sempre acompanhada do mal-estar, possa psicanaliticamente ser vista como algo superior em um sentido categórico.

Se a argumentação que apresentei a respeito das relações de caráter analógico entre fantasia e instinto estiver correta, será necessário aceitar também a existência de um disparate na defesa de que a tentativa de separar pulsão e instinto fundar-se-ia em um narcisismo mal elaborado ou mal analisado. Pois, tendo em vista

que o narcisismo é, grosso modo, o investimento de libido no próprio eu,

que a libido é a energia das pulsões sexuais, que, em nenhum momento, Freud, mesmo tendo a seu dispor o termo Instinkt, o situou nem como sinônimo de Trieb, nem mesmo como algo análogo a Trieb,

a acusação parece se valer implicitamente daquilo que ela explicitamente rejeita, sendo o conceito de narcisismo apenas concebível 
quando já se admitiu previamente que a necessidade de pensar a distinção entre natureza e cultura é constitutiva da psicanálise.

Talvez seja importante notar, por fim, que desde muito cedo a Verdrängung teve por modelo a noção de tradução. Não custa retomar rapidamente o trecho da carta de 6 de dezembro de 1896 da correspondência com W. Fliess, de acordo com a qual o mecanismo psíquico se forma por um processo de estratificação conforme a diferentes tipos de registros de traços mnêmicos. Freud sustenta a partir daí que

(...) os registros sucessivos representam conquistas psíquicas de fases sucessivas da vida. Na fronteira entre duas dessas fases é preciso que ocorra uma tradução do material psíquico. Explico as peculiaridades das psiconeuroses através da suposição de que essa tradução não se tenha dado no tocante a uma parte do material (...). Cada transcrição posterior inibe sua predecessora e esgota seu processo excitatório. Quando falta uma transcrição posterior, a excitação é tratada de acordo com as leis psicológicas vigentes no período psíquico precedente e seguindo as vias abertas naquela época. (...) Uma falba de tradução - eis o que se conbece clinicamente como "recalcamento". ${ }^{26}$

A despeito de todas as alterações por que passará a teoria freudiana, essa ideia terá vida longa. Por um lado, não se trata aqui da passagem de um texto a outro, já que não há representação-de-palavra no inconsciente, mas da passagem de uma forma de organização das representações para outra forma de organização. Por outro lado, o termo "tradução" [Übersetzung] aqui não é, para Freud, uma metáfora, mas a nomeação - ou ao menos a tentativa de nomeação - dos processos metapsicológicos que têm lugar na transição entre os sistemas psíquicos.

O fato de a psicanálise freudiana advogar, a partir daí, uma prática que insere em sua própria definição a noção de tradução já deveria ser forte motivo para nos alertar contra a caracterização da tradu-

26. FREUD, S. 6 de dezembro de 1896. In: MASSON, J. M. (Ed.) A correspondência completa de Sigmund Freud para Wilhelm Fliess (1887-1904). Trad. Vera Ribeiro. Rio de Janeiro: Imago Editora, 1986, carta 52, p. 209, grifo meu. 


\section{Léa Silveira}

ção de seus termos - e especialmente dos termos que referem seus conceitos centrais -como atitude sem consequências ou desprovida de compromissos. Se, com efeito, a tradução sempre trai, ela pode, no entanto, certamente, esforçar-se para ser menos eficaz no que diz respeito ao recalque do conteúdo do texto traduzido.

"Trieb" é, quanto a isso, um caso singular. Freud mesmo observou, não sem uma ponta de malícia, que este é "um termo que muitas línguas modernas nos invejam"27. Mas, além de "Trieb" ser um termo capaz, por si mesmo, de suscitar um pecado capital, ele designa na teoria freudiana algo novo. Pulsão é um conceito que Freud cria - de uma maneira, ademais, tateante, e não menos explícita por ser tateante; não é um conceito que ele tenha ido buscar pronto na biologia. $\mathrm{O}$ próprio texto metapsicológico sobre as pulsões e seus destinos ${ }^{28}$ seria desprovido de sentido se esse não fosse o caso. Assim, é preciso lembrar que não é apenas a especificidade do termo na língua que é envolvida nesse caso, mas também a especificidade do conceito na teoria: nem o primeiro possui equivalentes em outras línguas, nem o segundo possui paralelos em outras teorias, sejam quais forem suas respectivas naturezas.

Como se vê, não me dediquei, neste artigo, a defender o termo "pulsão" - embora eu o tenha empregado ao longo do texto -, mas a argumentar contra o termo "instinto". No entanto, não havendo na língua portuguesa um termo para fazer referência a um conceito ${ }^{29}$, a um significado técnico, por que, então, não lançar mão de um neologismo em vez de sobrepor à psicanálise um outro saber, o biológico, que a alimenta, é certo, mas com o qual ela não se identifica? Afinal, se é verdade que não precisamos ler Freud com Lacan, não é menos verdade que não precisamos destituir Freud de si mesmo.

27. FREUD, S. ¿Pueden los legos ejercer el análisis?(1926) In: Obras completas, v. XX. $2^{a}$ ed. Tradução de J. L. Etcheverry. Buenos Aires: Amorrortu Editores, 2010, p. 187.

28. FREUD, S. Pulsiones y destinos de pulsión (1915) In: Obras completas, v. XIV. $2^{a}$ ed. Tradução de J. L. Etcheverry. Buenos Aires: Amorrortu Editores, 2010.

29. Quanto à alternativa do termo "impulso", acredito que ele tende a perder de vista o aspecto de somação e a característica de força constante, que acompanham o conceito de Trieb em Freud. 


\section{Referências}

DE SOUZA, P. C. As palavras de Freud. São Paulo: Companhia das Letras, 2010.

Esta edição. In: FREUD, S. Obras completas, v. 14. Trad. P. C. de Souza. São Paulo: Companhia das Letras, 2010.

ESTÊVÃO, I. Retorno à querela do Trieb: Por uma tradução freudiana. Cadernos de filosofia alemã, São Paulo, v. XIX, 2012, pp. 79-105.

FREUD, S. 6 de dezembro de 1896. In: MASSON, J. M. (Ed.) A correspondência completa de Sigmund Freud para Wilhelm Fliess (1887-1904). Trad. Vera Ribeiro. Rio de Janeiro: Imago Editora, 1986.

Das Unbewußte. In: Psychologie des Unbewußten. Studienausgabe, v. III, Frankfurt am Main: Fischer Taschenbuch Verlag, 2000.

Aus der Geschichte einer infantile Neurose(1918[1914]). In: Zwei Kinder neurosen. Studienausgabe, v. VIII, Frankfurt am Main: Fischer Taschenbuch Verlag, 2000.

Der Mann Moses und die monotheistische Religion: DreiAbhandlungen (1939[1934-38]). In: _. Fragen der GesellschaftUrsprïnge der Religion. Studienausgabe, v. IX, Frankfurt am Main: Fischer Taschenbuch Verlag, 2000.

Pulsiones y destinos de pulsión (1915). In: Obras completas, v. XIV. $2^{a}$ ed. Trad. J. L. Etcheverry. Buenos Aires: Amorrortu Editores, 2010.

Loinconciente (1915). In: Obras completas, v. XIV. $2^{\text {a }}$ ed. Trad. J. L. Etcheverry. Buenos Aires: Amorrortu Editores, 2010.

De la historia de uma neurosis infantil (1918[1914]). In:

Obras completas, v. XVII. $2^{a}$ ed. Tradução de J. L. Etcheverry. Buenos Aires: AmorrortuEditores, 2010.

¿Pueden los legos ejercer el análisis? Diálogos con un juez imparcial (1926). In: Obras completas, v. XX. $2^{a}$ ed. Trad. J. L. Etcheverry. Buenos Aires: Amorrortu Editores, 2010.

Moisés y la religión monoteísta (1939[1934-38]). In:

Obras completas, v. XXIII. $2^{\mathrm{a}}$ ed. Tradução de J. L. Etcheverry. Buenos Aires: Amorrortu Editores, 2010.

GRUBRICH, I. Metapsychology and metabiology - On Sigmund Freud's draft Overview of the transference neuroses. In: FREUD, S. A phylogenetic fantasy - Overview of the transference neuroses. Cambridge, Massachusetts: Harvard University Press, 1987. 


\section{Léa Silveira}

LALANDE, A. Vocabulairetechnique et critique de lapbilosopbie (1902-1923). $6^{\mathrm{a}}$ ed. Paris: PUF, 1951.

LAPLANCHE, J. \& PONTALIS, J.-B. Vocabulaire de la psychanalyse. $13^{\mathrm{a}} \mathrm{ed}$. Paris: PUF, 1997.

SIMANKE, R. A psicanálise freudiana e a dualidade entre ciências naturais e humanas. Scientiae Studia, São Paulo, v. 7, 2009, pp. 221-236.

Recebido em 20.12.2013

Aceito em 17.02.2014 